\section{Reply to A. Phillips et al}

We are grateful to Phillips et $\mathrm{al}^{1}$ for their interest in our study evaluating surgeons' proficiency gain curves in relation to survival after esophageal cancer surgery in Sweden. ${ }^{2}$ This nationwide clinical cohort that we have constantly updated and further developed over the years has some important methodologic advantages that should not be ignored. The population-based design with complete and longterm follow-up of all patients who underwent surgery for esophageal cancer in Sweden counteracts selection bias, which is otherwise a main concern in studies evaluating surgical skills, particularly in singecenter studies. The fact that we have thoroughly collected all important prognostic factors including tumor stage and comorbidity on all patients is another important advantage of the cohort. We believe that the scientific validity of the study is the key for making it possible to draw conclusions that can potentially influence clinical practice.

We cannot examine the overall experience of the individual surgeons evaluated in this cohort, but generally, the surgeons performing esophagectomies in Sweden have a long experience of surgery for various conditions and subspecialization in upper GI surgery before they move on to performing esophagectomies. These operations are usually conducted by the most experienced upper GI consultant surgeons available at the performing hospital. These surgeons have gained experience over many years for how to manage various complications after GI surgery, including those relating to esophagectomy, before they start performing esophagectomies. The high quality of the surgery is well documented by the low population-based (unselected) postoperative mortality rates in Sweden; data from earlier versions of the present cohort show that the 30 -day mortality was only $4.9 \%$ in 1997 to 2000 and $2.0 \%$ in 2001 to $2005 .^{3,4}$ Also, the long-term population-based survival after surgery competes well internationally, with a 5-year survival of $31 \%$ since $1997.3,4$

The annual surgery volume for esophageal cancer is definitely an important prognostic factor. ${ }^{5}$ This is one of the main reasons for conducting the current study. However, some data indicate that annual surgeon volume is more relevant than annual hospital volume alone. We used data from an earlier version of the present cohort to evaluate this issue and found that surgeon volume remained a strong prognostic factor after adjusting for hospital volume, whereas hospital volume did not remain a prognostic factor after adjusting for surgeon volume. ${ }^{6}$

Any effect of training on the learning curve of lymphadenectomy is outside the scope of the article and cannot be examined by the data. Nevertheless, the lymph node yield shown in our article ${ }^{2}$ is a surrogate to the extent of lymphadenectomy.

We agree that centralization of esophagectomy has contributed to improving the results after esophageal cancer surgery. In Sweden, the incidence of esophageal cancer is low, which stresses the need for centralization even more. The number of cases per surgeon is clearly lower than in countries with higher incidence (eg, United Kingdom). Yet, the survival rates after esophagectomy in Sweden are good, indicating that the quality of this surgery is still maintained. ${ }^{3,4}$ Nevertheless, we do agree that further centralization will provide an environment for surgical mentorship and probably improve the prognosis in patients with esophageal cancer in the future. We did not claim that surgeons could reach competency with a small number of procedures. In contrast, performing a large number of procedures does not by itself guarantee competency.

Specifically, $23.0 \%$ and $8.6 \%$ of surgeons reached the change points for 30-day and 3-year mortality at 15 and 35 esophagectomies, respectively. The risk-adjusted cumulative sum results are the average results for surgeons performing esophagectomy within the data set. Obviously, the proficiency-gain curves are expected to be individual between different surgeons. Having said that, it is nevertheless important to provide figures based on a large number of individual surgeons that can help guide clinical practice. Moreover, excellence in surgery is not just a technical skill; the main challenges are often how to deal with patient selection and postoperative complications.

We believe, in agreement with Phillips et $\mathrm{al}^{1}{ }^{1}$ that surgeons who aim to conduct esophagectomy for cancer should be included in structured training programs and be trained in high-volume centers that have a wide range of experience in such surgery. This could substantially improve the prognosis in patients diagnosed with esophageal cancer.

\section{Sheraz R. Markar}

Imperial College London, London, United Kingdom; and Karolinska Institutet, Stockholm, Sweden

\section{Hugh Mackenzie}

Imperial College London, London, United Kingdom

\section{Pernilla Lagergren}

Karolinska Institutet, Stockholm, Sweden

\section{George B. Hanna}

Imperial College London, London, United Kingdom

\section{Jesper Lagergren}

Karolinska Institutet, Stockholm, Sweden; and King's College London, London, United Kingdom

\section{AUTHORS' DISCLOSURES OF POTENTIAL CONFLICTS OF INTEREST}

Disclosures provided by the authors are available with this article at www.jco.org.

\section{REFERENCES}

1. Phillips AW, Dent $B$, Navidi $M$, et al: Surgical proficiency in the era of centralization. J Clin Oncol 34:3939-3940, 2016

2. Markar SR, Mackenzie $H$, Lagergren $P$, et al: Surgical proficiency gain and survival after esophagectomy for cancer. J Clin Oncol 34:1528-1536, 2016

3. Rouvelas I, Zeng W, Lindblad M, et al: Survival after surgery for oesophageal cancer: A population-based study. Lancet Oncol 6:864-870, 2005 


\section{Correspondence}

4. Rutegård $M$, Charonis $K, L u Y$, et al: Population-based esophageal cancer survival after resection without neoadjuvant therapy: An update. Surgery 152 903-910, 2012

5. Wouters MW, Gooiker GA, van Sandick JW, et al: The volume-outcome relation in the surgical treatment of esophageal cancer: A systematic review and meta-analysis. Cancer 118:1754-1763, 2012
6. Derogar M, Sadr-Azodi O, Johar A, et al: Hospital and surgeon volume in relation to survival after esophageal cancer surgery in a population-based study. J Clin Oncol 31:551-557, 2013

DOI: $10.1200 / J C O .2016 .69 .1113$; published online ahead of print at www.jco.org on August 29, 2016. 


\section{AUTHORS' DISCLOSURES OF POTENTIAL CONFLICTS OF INTEREST}

Reply to A. Phillips et al

The following represents disclosure information provided by authors of this manuscript. All relationships are considered compensated. Relationships are self-held unless noted. I = Immediate Family Member, Inst = My Institution. Relationships may not relate to the subject matter of this manuscript. For more information about ASCO's conflict of interest policy, please refer to www.asco.org/rwc or jco.ascopubs.org/site/ifc.

\section{Sheraz R. Markar}

No relationship to disclose

Hugh Mackenzie

No relationship to disclose

Pernilla Lagergren

No relationship to disclose

\section{George B. Hanna}

No relationship to disclose

\section{Jesper Lagergren}

No relationship to disclose 